\title{
Outcomes of Deferred Revascularization Following Physiological Coronary Assessment Using Fractional Flow Reserve
}

\author{
Shabbir Ali Shaik ${ }^{1} \quad$ Aramalla Sunitha ${ }^{1} \quad$ Indrani Garre ${ }^{1} \quad$ VS Bharathi Lakshmi ${ }^{1}$ \\ ${ }^{1}$ Department of Cardiology, Nizam's Institute of Medical Sciences, \\ Address for correspondence V. S. Bharathi Lakshmi, MD, DM, \\ Hyderabad, Telangana, India \\ Department of Cardiology, Nizam's Institute of Medical Sciences, \\ Punjagutta, Hyderabad, Telangana 500082, India \\ (e-mail: bharathivanaparty@gmail.com).
}

Ind J Car Dis Wom 2019;4:190-194

\begin{abstract}
Keywords

- fractional flow reserve (FFR)

- target lesion revascularization (TLR)

- myocardial infarction (MI)

- major adverse cardiovascular events (MACE)

- percutaneous coronary intervention $(\mathrm{PCl})$

Objective Outcomes of patients with deferred revascularization for intermediate stenosis coronary lesion based upon physiological assessment using fractional flow reserve $([F F R]>0.80)$.

Methods Patients with chest pain with angiographic intermediate stenosis, (40-70\% stenosis) without noninvasive test evidence of ischemia were selected and underwent an FFR assessment between January 1, 2015, and August 31, 2018. Patients with intermediate lesions of FFR $>0.80$ were followed, and those patients with lesion with FFR $<0.8$ were excluded from the study. The primary outcomes of the study were to know the composite of target lesion revascularization (TLR), myocardial infarction (MI), and other vascular complications (major adverse cardiovascular events [MACE]).

Results In 102 patients who underwent deferred revascularization (FFR >0.80), 104 FFR studies were done and followed over one year. Four patients needed target lesion revascularization (3.92\%). Three patients underwent percutaneous coronary intervention $(2.94 \%)$ within nine months of follow-up, and one patient underwent coronary artery bypass graft (CABG) $(0.98 \%)$ at one year of follow-up. Two patients died with acute $\mathrm{MI}$ with sudden cardiac arrest (1.96\%). Two patients developed right hemiparesis $(2.94 \%)$ on one year of follow-up due to acute ischemic stroke of a middle cerebral artery, and one patient underwent permanent pacemaker implantation for complete heart block (CHB). The incidence of the total events was $8.82 \%$, TLR was $3.92 \%$, Coronary event rate was $5.88 \%$, and MACE was $7.84 \%$.

Conclusions Our study shows that there was a significant increase in the incidence of coronary event rate $(5.88 \%)$ and the MACE rate $(7.84 \%)$ in patients of deferred coronary revascularization based on higher FFR values $(>0.8)$.
\end{abstract}

\section{Introduction}

Percutaneous coronary intervention (PCI) has been shown to improve the symptomatic state and mortality benefit in acute coronary syndromes, but not in chronic stable angina. ${ }^{1-5}$ Physiological assessment by fractional flow reserve (FFR)-guided PCI is better for long outcomes than the anatomical severity of the lesion..$^{6-9}$ The differed PCI as there is $>0.8$ of FFR value shown to be beneficial in previous studies. ${ }^{10-12}$ We want to see the accuracy of an FFR cutoff value of 0.8 to predict the coronary events at one year.

\section{Objective}

This study aims to assess the outcome of intermediate stenosis coronary lesions whose revascularization was deferred based on FFR values $\leq 0.8$.
DOI https://doi.org/ 10.1055/s-0039-3402825
C 2019 Women in Cardiology and Related Sciences
License terms

() (1) $\ominus \circledast$ 


\section{Methods}

\section{Study Design: An Observational Study}

Inclusion criteria include the following:

1. Patients with an acute coronary syndrome or chronic stable angina, with

2. Presence of at least one stenosis, of 40 to $70 \%$ in one major native epicardial coronary artery supplying viable myocardium.

Exclusion criteria include the following:

1. Presence of thrombus

2. Distal thrombolysis in Myocardial infarction (TIMI) flow $<3$

3. Spontaneous dissection or ulcerated plaque

- Number of enrolled: 102

- Duration of follow-up: 1 year

The study was conducted at our center; we analyzed all procedures between January 1, 2015, and August 31, 2018, which involved the FFR measurement of the angiographically moderate (40-70\%) stenosis lesion on visual assessment.

\section{FFR Procedure}

As per the standard protocol, all patients are loaded with dual antiplatelets, that is, aspirin (325 mg of loading dose) and clopidogrel (75 $\mathrm{mg}$ or $600 \mathrm{mg}$ loading dose if not taking previously) before taken to the procedure. After securing intra-arterial access, 5,000 U intravenous heparin sodium was administered. Using a 6-Fr appropriate guide catheter, angiographic projections were taken, to get the best possible view of the lesion, with greatest diameter stenosis by visual assessment without any superimposed branches. The physiological assessment was done with a 0.014" FFR intracoronary pressure wire (wireless FFR). FFR is measured by administering intracoronary adenosine. The optimal dose of adenosine given for the right coronary artery was $100 \mu \mathrm{g}$ and for left coronary artery was $200 \mu$ g. Special precautions were taken not to wedge the guide catheter to the coronary ostium after giving injection adenosine bolus. Maximal hyperemia was confirmed by the fall of arterial pressure with bradycardia. FFR was measured during maximal hyperemia. For all lesions, FFR was calculated for at least 2 times, and the lowest value obtained was taken for deciding revascularization. Lesions with FFR of $\geq 0.8$ were deferred.

\section{Follow-up}

All enrolled patients in the study were followed for a minimum of one year. Follow-up was conducted by regular outpatient visits, telephonic interviews, and the medical records of patients were taken when they are hospitalized during the study period.

\section{Statistical Analysis}

All the variables were taken in percentages to represent, and binary logistic regression analysis was done for events with other factors using Minitab version 17 (Minitab Ltd., United Kingdom).

\section{Results}

Between the period of January 1, 2015, and August 31, 2018, 102 patients (with a mean age of 58.1 years) who fulfilled our inclusion criteria were recruited. The baseline characteristics of the study population are shown in - Table $\mathbf{1}$ and -Fig. 1. Among them, one-third were females.

We studied 104 lesions in 102 patients. In 2 patients, we studied two lesions (1.9\%); the adverse events observed during the procedure were transient episodes of atrioventricular block and nonspecific chest pain after injecting adenosine bolus, which reverted spontaneously. Of the coronary lesions studied, most of them nearly $73.78 \%$ in a left anterior descending coronary artery (LAD), second common in the right coronary artery (RCA) followed by left circumflex artery (LCX) $11.76 \%$ and 9.8\%, respectively, as shown in - Fig. 2.

All 102 patients were followed-up for one year. The mean FFR value observed in the study was $0.8938 \pm 0.041$. Three men, aged 64, 52, and 53 years, expired during follow-up of FFR $0.96,0.86$, and 0.86 , respectively. The incidence of the total events was $8.82 \%$, TLR was $3.92 \%$. The coronary event rate was $5.88 \%$. MACE was $7.84 \%$.

Two patients died in 10 months with acute myocardial infarction (MI) with sudden cardiac arrest (FFR 0.96 and 0.86 ). Three patients, aged 71,65 , and 60 years, were admitted (FFR 0.92, 0.96, 0-91) with one year following discharge for unstable angina, and PCI was done for the lesions which studied previously during FFR. One patient aged 54 years of FFR 0.88 in LAD and insignificant lesions in other territories with exertional angina underwent coronary artery bypass graft (CABG) due to rapid progression of obstructive atherosclerosis at one year. Two patients aged 61 years (FFR 0.87) and 64 years (FFR 0.89) developed cerebrovascular accident (right hemiparesis) at 10 months. One patient aged 73 years

Table 1 Baseline patient characteristics

\begin{tabular}{|l|l|}
\hline Variable & Parameter \\
\hline Patients total & 102 \\
\hline Age (years) mean \pm standard deviation & $58.1 \pm 10.06$ \\
\hline Male (\%) & $68(66.67 \%)$ \\
\hline Female (\%) & $34(33.33 \%)$ \\
\hline
\end{tabular}

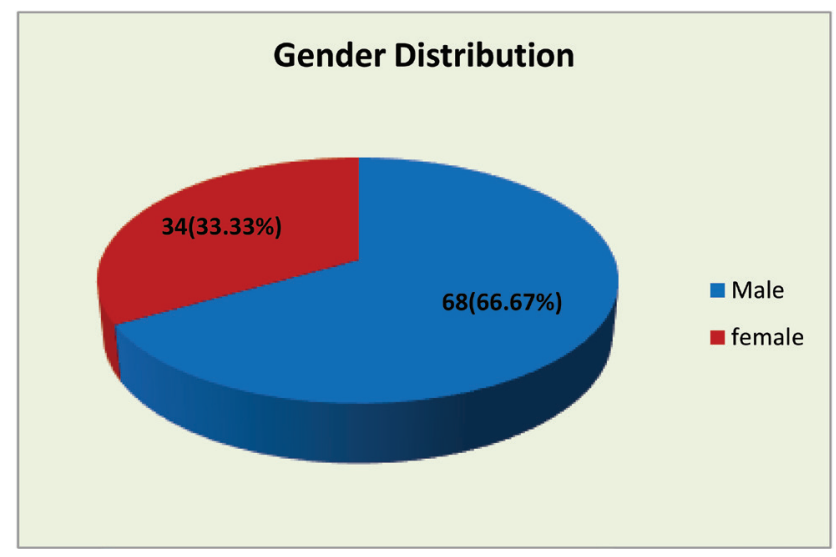

Fig. 1 Gender distribution. 


\section{lesions for which FFR done (\%)}

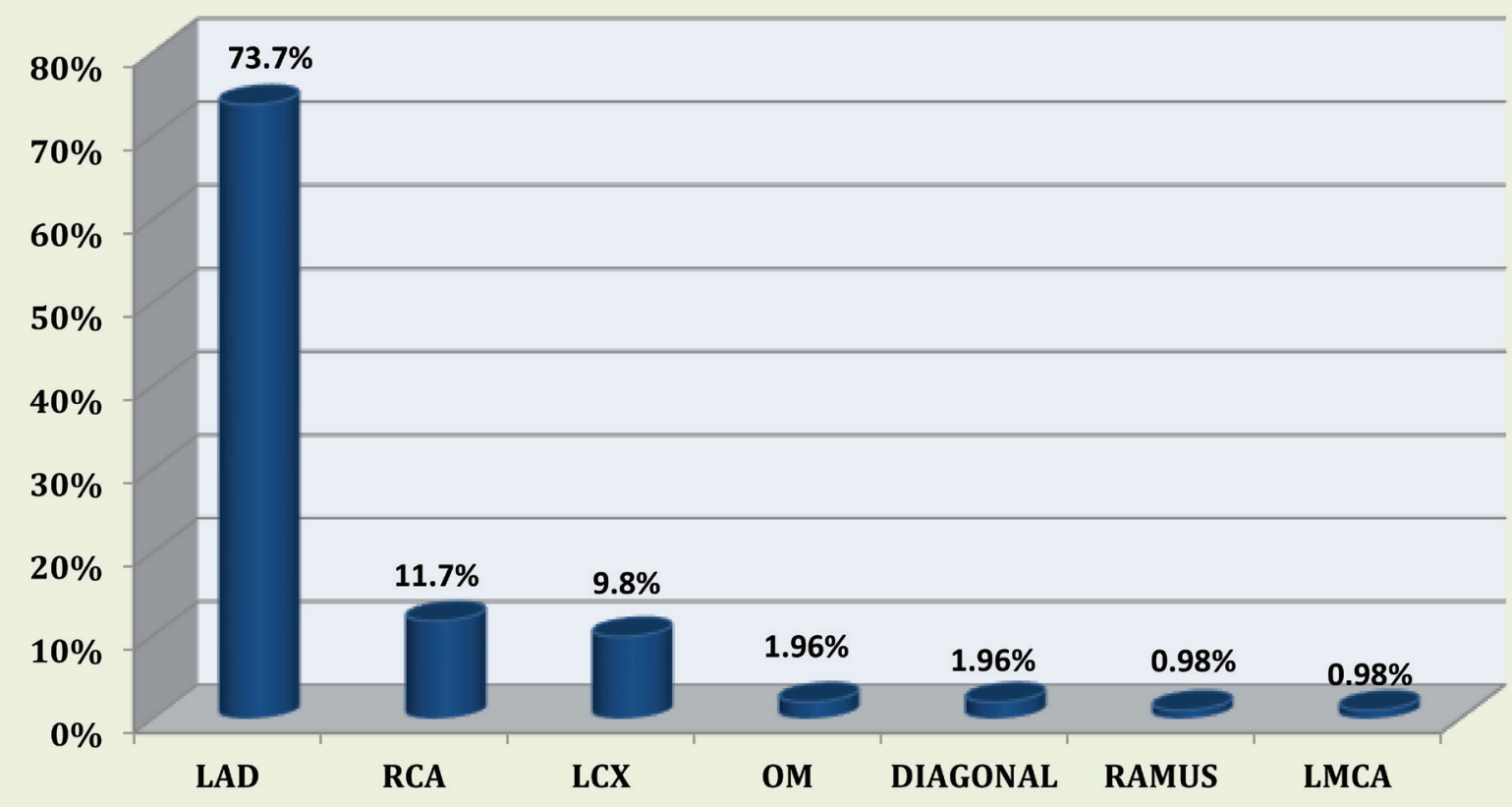

Fig. 2 Bar diagram showing the description of FFR lesion containing coronary vessel.

(FFR 0.94) developed degenerative conduction system diseases (complete heart block) unrelated to coronary artery disease and underwent permanent pacemaker implantation at 11 months of follow-up; $91.18 \%$ of patients remained free of events (-Table 2 and - Fig. 3 ).

Binary logistic regression showed that MACE was not dependent on age, FFR, and sex (-Table 3 ).

\section{Discussion}

FFR calculated using pressure wire was proved to be a useful parameter for determining the physiological significance of angiographically intermediate stenosis lesions ${ }^{1-10}$ and in deciding the revascularization. ${ }^{11}$ Not only in single-vessel disease, but its value is also proved in multivessel coronary artery disease.

Table 2 Details of Events at one year

\begin{tabular}{|l|l|l|}
\hline Parameter & $\begin{array}{l}\text { No. } \\
(\%)\end{array}$ & $\begin{array}{l}\text { Percentage of total patients } \\
(\%)\end{array}$ \\
\hline $\begin{array}{l}\text { Events total } \\
\text { no.(\%) }\end{array}$ & 9 & $8.82 \%$ \\
\hline PCI & $3(34 \%)$ & $2.94 \%$ \\
\hline CABG & $1(11 \%)$ & $0.98 \%$ \\
\hline MI & $2(22 \%)$ & $1.96 \%$ \\
\hline CVA & $2(22 \%)$ & $1.96 \%$ \\
\hline PPI & $1(11 \%)$ & $0.98 \%$ \\
\hline
\end{tabular}

Abbreviations: $\mathrm{PCl}$, percutaneous coronary intervention; $\mathrm{CABG}$, coronary artery bypass graft; MI, myocardial infarction; CVA, cerebrovascular accident; PPI, permanent pace maker.

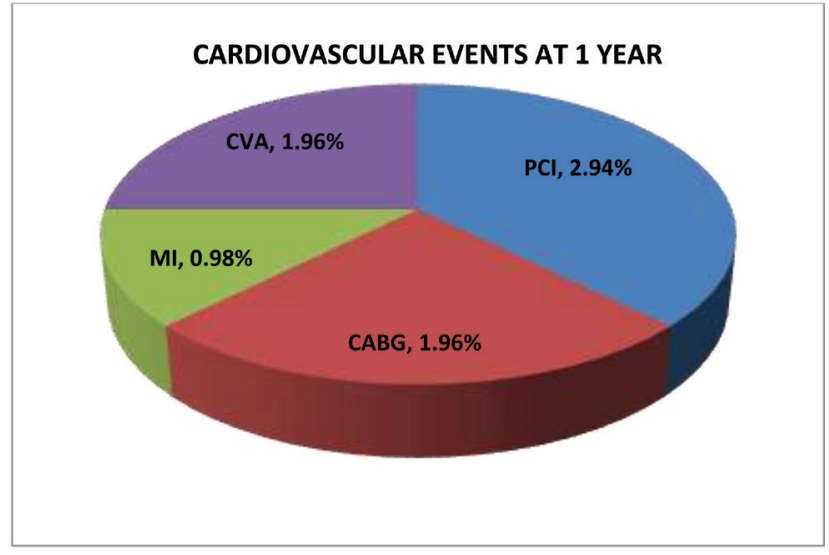

Fig. 3 Cardiovascular events at one year.

Table 3 Determinants of MACE by binary logistic regression

\begin{tabular}{|l|l|l|}
\hline Variables & Chi-square & P-value \\
\hline Regression constant & 2.04 & 0.565 \\
\hline Age $(y)$ & 1.13 & 0.388 \\
\hline FFR & 0.45 & 0.504 \\
\hline Sex & 0.17 & 0.682 \\
\hline
\end{tabular}

Abbreviations: MACE, major adverse cardiovascular events; FFR, fractional flow reserve.

FFR was significantly underutilized in the clinical practice even though the data have shown long-term benefits and improved outcomes with FFR-guided PCI, which is used only in $6.1 \%$ of interventions for intermediate coronary lesions (40-70\% stenosis). ${ }^{12,13}$ FAME 2 trial confirmed the 
usefulness of FFR-guided PCI, as there were less MACE rates in PCI deferred patients. Various studies comparing FFR with noninvasive functional testing has demonstrated a good correlation. The cutoff values for the physiological significance of FFR were 0.75 , which denotes that coronary pressure is reduced by $25 \%$ from normal. However, it was validated from various randomized trials, for increasing the sensitivity of FFR, the cut values were increased to $0.80 .{ }^{14}$

In our study, neither the FFR value nor the demographic factors (age/sex) found statistical significance in causing the events. FAME substudy has shown that female patients have higher FFR value for a given severity of coronary artery stenosis, and FFR-guided PCI just as beneficial in women as for men. Even though in our study we have not seen the comparable values in women and men, the study showed that there was no difference in MACE rates in patients of either sex in whom revascularization differed based on FFR values.

As we excluded the lesions with angiographic signs of instability like the presence of visible thrombus, dissections, ulcerations, we cannot extrapolate our data to these lesions to predict the event rates when FFR values are low in those population.

Recent data show there is limitation even for FFR. Hence, additional invasive hemodynamics for measurement of the functional significance of intermediate lesions like resting full cycle ratio (RFR) and instantaneous wave-free ratio (iFR) need to be considered. iFR-SWEDEEHEART trail and DEFINEFLAIR trail showed iFR was noninferior to FFR for physiological assessment of coronary artery stenosis in relation to subsequent clinical outcomes and had less periprocedural complications and shorter procedural times. A study by Sen et al showed that in LAD lesions, iFR-guided deferral is safer than FFR-guided deferral and significantly lower MACE rates. ${ }^{15}$ However, our study was only with FFR, not in comparison with other functional modalities of assessment.

In the present study, FFR measurement in all patients was done with the administration of intracoronary adenosine. Various studies have shown that intracoronary adenosine has achieved a lower level of hyperemia than intravenous adenosine. ${ }^{16-19}$ One comparative study showed that there is no statistical significance difference between intravenous and intracoronary administration of $150 \mu$ g adenosine, ${ }^{20}$ and another study showed maximum hyperemia with intracoronary adenosine. ${ }^{21}$ In our study, the intracoronary adenosine dose used for the left system was $200 \mu \mathrm{g}$, and the right system was $100 \mu$ g, given after the properly aligned engagement of the guide catheter.

Additional imaging with OCT along with FFR was studied in the FORZA study (Fractional Flow Reserve versus optical coherence tomography [OCT] to Guide RevasculariZAtion of Intermediate Coronary Stenoses). This study showed a decreased occurrence of acute kidney injury (AKI), hospitalizations duration, overall cost burden, and MACE rates and angina at 13 months. Probably this advantage is due to the morphological guidance by the OCT in addition to physiological significance. ${ }^{22}$

The results of our study give the information that FFR measured with the intracoronary pressure wire alone, may not be a sufficient tool for guiding revascularization in patients admitted with moderate coronary lesions. Probably addition of clinical data like risk factors, especially diabetes mellitus, clinical presentation, left ventricular function, prior PCI/ CABG status, and associated comorbidities along with FFR values are better predictors for the MACE. The introduction of combined fusion imaging like IVUS with FFR may predict the complexity of the lesion better than a single test.

\section{Limitations}

Important contributing factors for the outcome like diabetes, LV dysfunction, and ACS presentation were not considered for the multivariate analysis.

\section{Conclusions}

The present study shows that there was an increased incidence of target lesion failure (5.88\%) in patients of FFR deferred revascularization, in contrast to previous studies. As already mentioned in limitations, further analysis in patients with diabetes, LV dysfunction, and ACS subgroup was not done.

\section{Recommendations}

Probably combined clinical, morphological (intravascular imaging like optical coherence tomography), and functional assessment of the lesions may be more appropriate than only FFR.

\section{Conflict of Interest}

None.

\section{References}

1 Pijls NH, Van Gelder B, Van der Voort P, et al. Fractional flow reserve. A useful index to evaluate the influence of an epicardial coronary stenosis on myocardial blood flow. Circulation 1995;92(11):3183-3193

2 Pijls NH, De Bruyne B, Peels K, et al. Measurement of fractional flow reserve to assess the functional severity of coronaryartery stenoses. N Engl J Med 1996;334(26):1703-1708

3 Kern MJ, Lerman A, Bech JW, et al; American Heart Association Committee on Diagnostic and Interventional Cardiac Catheterization, Council on Clinical Cardiology. Physiological assessment of coronary artery disease in the cardiac catheterization laboratory: a scientific statement from the American Heart Association Committee on Diagnostic and Interventional Cardiac Catheterization, Council on Clinical Cardiology. Circulation 2006;114(12):1321-1341

4 Uren NG, Melin JA, De Bruyne B, Wijns W, Baudhuin T, Camici PG. Relation between myocardial blood flow and the severity of coronary-artery stenosis. N Engl J Med 1994;330(25):1782-1788

5 De Bruyne B, Baudhuin T, Melin JA, et al. Coronary flow reserve calculated from pressure measurements in humans. Validation with positron emission tomography. Circulation 1994;89(3):1013-1022

6 Bech GJ, De Bruyne B, Bonnier HJ, et al. Long-term follow-up after deferral of percutaneous transluminal coronary angioplasty of intermediate stenosis on the basis of coronary pressure measurement. J Am Coll Cardiol 1998;31(4):841-847

7 Domínguez-Franco AJ, Jiménez-Navarro MF, Muñoz-García AJ, Alonso-Briales JH, Hernández-García JM, de Teresa Galván E. Pronóstico a largo plazo de diferir la intervención coronaria en 
diabéticos sobre la base de la reserva fraccional de flujo. Rev Esp Cardiol 2008;61(4):352-359

8 Pijls NH, van Schaardenburgh P, Manoharan G, et al. Percutaneous coronary intervention of functionally nonsignificant stenosis: 5-year follow-up of the DEFER Study. J Am Coll Cardiol 2007;49(21):2105-2111 10.1016/j.jacc.2007.01.087

9 Kern MJ, Donohue TJ, Aguirre FV, et al. Clinical outcome of deferring angioplasty in patients with normal translesional pressure-flow velocity measurements. J Am Coll Cardiol 1995;25(1):178-187

10 Chamuleau SA, Meuwissen M, Koch KT, et al. Usefulness of fractional flow reserve for risk stratification of patients with multivessel coronary artery disease and an intermediate stenosis. Am J Cardiol 2002;89(4):377-380

11 Dattilo PB, Prasad A, Honeycutt E, Wang TY, Messenger JC. Contemporary patterns of fractional flow reserve and intravascular ultrasound use among patients undergoing percutaneous coronary intervention in the United States: insights from the National Cardiovascular Data Registry. J Am Coll Cardiol 2012;60(22):2337-2339

12 Christou MA, Siontis GC, Katritsis DG, Ioannidis JP. Meta-analysis of fractional flow reserve versus quantitative coronary angiography and noninvasive imaging for evaluation of myocardial ischemia. Am J Cardiol 2007;99(4):450-456

13 Tonino PA, De Bruyne B, Pijls NH, et al; FAME Study Investigators. Fractional flow reserve versus angiography for guiding percutaneous coronary intervention. N Engl J Med 2009;360(3):213-224 10.1056/NEJMoa0807611 | Medline

14 De Bruyne B, Sarma J. Fractional flow reserve: a reviewinvasive imaging. Heart 2008;94(7):949-959 10.1136/ hrt.2007.122838 | Medline

15 Sen S, Ahmad Y, Dehbi HM, et al. Clinical events after deferral of LAD revascularization following physiological coronary assessment. J Am Coll Cardiol 2019;73(4):444-453
16 De Bruyne B, Pijls NH, Barbato E, et al. Intracoronary and intravenous adenosine 5 '-triphosphate, adenosine, papaverine, and contrast medium to assess fractional flow reserve in humans. Circulation 2003;107(14):1877-1883 10.1161/01. CIR.0000061950.24940.88

17 Jeremias A, Filardo SD, Whitbourn RJ, et al. Effects of intravenous and intracoronary adenosine 5 '-triphosphate as compared with adenosine on coronary flow and pressure dynamics. Circulation 2000;101(3):318-323

18 Di Segni E, Higano ST, Rihal CS, Holmes DR, Jr, Lennon R, Lerman A. Incremental doses of intracoronary adenosine for the assessment of coronary velocity reserve for clinical decision making. Catheter Cardiovasc Interv 2001;54(1):34-40

19 López-Palop R, Saura D, Pinar E, et al. Adequate intracoronary adenosine doses to achieve maximum hyperaemia in coronary functional studies by pressure derived fractional flow reserve: a dose response study. Heart 2004;90(1):95-96

20 Casella G, Leibig M, Schiele TM, et al. Are high doses of intracoronary adenosine an alternative to standard intravenous adenosine for the assessment of fractional flow reserve? Am Heart J 2004;148(4):590-595

21 Yoon MH, Tahk SJ, Yang HM, et al. Comparison of the intracoronary continuous infusion method using a microcatheter and the intravenous continuous adenosine infusion method for inducing maximal hyperemia for fractional flow reserve measurement. Am Heart J 2009;157(6):1050-1056

22 Leone AM, Burzotta F, Aurigemma C, et al. Prospective randomized comparison of fractional flow reserve versus optical coherence tomography to guide revascularization of intermediate coronary stenoses: one-month results. J Am Heart Assoc 2019;8(15):e012772 